\title{
Viabilidade de sementes de castanha-do-Brasil pelo teste de tetrazólio
}

\author{
Daniela Roberta BORELLA ${ }^{1 *}$, Andréa Carvalho da SILVA², Júlio Henrique Germano de SOUZA², \\ Charles Campoe MARTIM ${ }^{1}$, Mariana PIZZATTO², Kalisto Natam Carneiro SILVA² \\ ${ }_{1}^{1}$ Programa de Pós-Graduação em Física Ambiental, Universidade Federal de Mato Grosso, Cuiabá, MT, Brasil. \\ (ORCID: *; 0000-0003-2955-0105) \\ 2Instituto de Ciências Agrárias e Ambientais, Universidade Federal de Mato Grosso, Sinop, MT, Brasil. \\ (ORCID: 0000-0003-2921-3379; 0000-0001-5233-2064; 0000-0001-5751-0368; 0000-0001-9755-9086) \\ *E-mail: drborella@gmail.com (ORCID: 0000-0003-2941-2116)
}

Recebido em 04/11/2019; Aceito em 09/04/2020; Publicado em 24/04/2020.

\begin{abstract}
RESUMO: Objetivou-se revisar e propor o protocolo de viabilidade das sementes da Bertholletia excelsa pelo teste de tetrazólio. Sementes oriundas de plantio comercial propagado por enxertia com 16 anos de idade implantadas na Fazenda Iracema em Cláudia, MT, foram destegumentadas e cortadas longitudinalmente, depois foram hidratadas em água por imersão direta (ID) e papel toalha Germitest ${ }^{\mathbb{B}}$ (PG) por 24 e 48 h e embebidas nas concentrações de 0,1 e $0,5 \%$ do sal de tetrazólio por 12 e $24 \mathrm{~h}$ no escuro à $30^{\circ} \mathrm{C}$. O delineamento experimental foi completamente randomizado em fatorial $2 \times 2 \times 2 \times 2$ (forma de embebição $\times$ tempo em embebição x tempo em solução de tetrazólio x concentração da solução de tetrazólio) com quatro repetições de 8 sementes. O teste de tetrazólio foi eficiente para colorir e identificar as sementes viáveis e inviáveis. A avaliação da viabilidade das sementes da B. excelsa destegumentadas e partidas ao meio foi melhor na condição de embebição com imersão direta em água por $24 \mathrm{~h}$ e concentração de $0,5 \%$ do sal tetrazólio por $24 \mathrm{~h} \mathrm{à} 30^{\circ} \mathrm{C}$ e embebição em papel toalha Germitest ${ }^{\circledR}$ por $24 \mathrm{~h}$ e concentração de $0,5 \%$ do sal tetrazólio por $12 \mathrm{~h}$ à $30^{\circ} \mathrm{C}$. Palavras-chave: Bertbolletia excelsa Humb. \& Bonpl; potencial fisiológico; sementes florestais; recalcitrância.
\end{abstract}

\section{Viability of brazil nuts seeds by tetrazolium test}

\begin{abstract}
The objective was to review and propose the protocol of viability of Bertholletia excelsa seeds by tetrazolium test. Seeds from the commercial planting propagated by grafting with 16-year-old implanted at Fazenda Iracema in Cláudia, MT, were undegumented and cut longitudinally, then hydrated in water by direct immersion (ID) and Germitest ${ }^{\circledR}$ paper towel (PG) for 24 and $48 \mathrm{~h}$ and soaked in concentrations of 0.1 and $0.5 \%$ of tetrazolium salt for 12 and $24 \mathrm{~h}$ in the dark at $30^{\circ} \mathrm{C}$. The experimental design was completely randomized in a factorial design $2 \times 2 \times 2 \times 2$ (soaking form x soaking time $\mathrm{x}$ time in tetrazolium solution $\mathrm{x}$ tetrazolium solution concentration) with four replications of 8 seeds. The tetrazolium test was efficient to color and identify viable and unviable seeds. The evaluation of viability of detegumented and cut longitudinally $B$. excelsa seeds was better in: direct soaking in water for $24 \mathrm{~h}$ and concentration of $0.5 \%$ of tetrazolium salt for 24 $\mathrm{h}$ at $30^{\circ} \mathrm{C}$ and soaking in Germitest ${ }^{\circledR}$ paper towels for $24 \mathrm{~h}$ and a concentration of $0.5 \%$ of the tetrazolium salt for $12 \mathrm{~h}$ at $30^{\circ} \mathrm{C}$.
\end{abstract}

Keywords: Bertholletia excelsa Humb. \& Bonpl; physiological potential; forest seeds; recalcitrance.

\section{INTRODUÇÃO}

Bertholletia excelsa Humb. \& Bonpl. conhecida por castanheira-do-Brasil, produz sementes oleaginosas comestíveis de alto valor nutricional compostas com até $70 \%$ de lipídios, $17 \%$ de proteínas, selênio, fibras, vitaminas B1 e B2, riboflavina, niacina, tiamina (YANG, 2009), minerais como nitrogênio, fósforo, cálcio, magnésio, zinco, boro e outros (BOUVIÉ et al., 2016). As amêndoas, assim chamadas, movimentam a economia nacional e internacional, representando para várias comunidades extrativistas da Floresta Amazônica Matogrossense 76,6\% da renda familiar (TONINI et al., 2017), a produtividade dos castanhais na safra 2018 aumentou 46,3\% cerca de 34.170 toneladas e o valor da produção chegou a $\mathrm{R} \$ 130,9$ milhões um crescimento de 35,4\% (IBGE, 2018).

Além da importância socioeconômica, a castanheira-doBrasil é uma espécie dominante de interação mútua com os organismos que vivem na floresta. Ainda assim, sofre intensas pressões antropogênicas e naturais, que comprometem a perpetuação da espécie. As condições ambientais, juvenilidade (TEIXEIRA et al., 2015) e a disponibilidade de nutrientes via solo (COSTA et al., 2017) podem influenciar na produtividade, biomassa e dispersão de frutos e sementes, bem como, na qualidade fisiológica das sementes.

As sementes apresentam comportamento recalcitrante, são muito sensíveis a redução da umidade (FIGUEIRÊDO et al., 1990) e a longo período de armazenamento em ambiente laboratorial, o que compromete a qualidade fisiológica das sementes e a propagação da espécie (CAMARGO et al., 1997). Somado à recalcitrância, as sementes apresentam processo germinativo desuniforme e lento de 6 a 18 meses (MÜLLER et al., 1980). Possivelmente, um dos principais obstáculos é a dificuldade de hidratação do 
embrião devido à grande quantidade de reservas (lipídeos, substâncias hidrofóbicas) e/ou por um balanço hormonal interno que dificulta a regeneração da espécie (CAMARGO et al., 2000).

Classificar o potencial de viabilidade das sementes é essencial para garantir o controle de qualidade, nesse sentido, o teste de tetrazólio é o mais empregado para avaliar a qualidade fisiológica das sementes, classificando por meio dos índices de viabilidade e de vigor as classes de qualidade das sementes de um mesmo lote (FRANÇA-NETO; KRZYZANOWSKI, 2019). Além de ser um teste rápido que pode substituir o teste padrão de germinação.

O teste de tetrazólio identifica tecidos das sementes que apresentam atividade respiratória, a partir da redução do sal 2, 3, 5 trifenil cloreto ou brometo de tetrazólio pela atividade das enzimas desidrogenases que catalisam reações respiratórias nas mitocôndrias, durante a glicólise e ciclo do ácido cítrico, sobretudo, malato desidrogenase (FRANÇANETO; KRZYZANOWSKI, 2019). A solução de tetrazólio penetra na semente reagindo com os íons de hidrogênio liberados da respiração celular, resultando na redução do sal a substância vermelha, estável, não difusível chamado trifenilformazan ou formazan (ABBADE; TAKAKI, 2014).

Diversos estudos com espécies agrícolas e hortícolas permitiram adequar procedimentos padrão de viabilidade de sementes pelo teste de tetrazólio (FRANÇA-NETO et al., 1998; SILVA et al., 2013; REZENDE et al., 2015; RODRIGUES et al, 2018; PARAÍSO et al., 2019) e entre outros. $\mathrm{Na}$ área florestal, apesar dos trabalhos desenvolvidos com espécies nativas Copaifera langsdorffii e Schizolobium parabyba (FOGAÇA et al., 2011) Ceiba speciosa (LAZAROTTO et al., 2011), Enterolobium contortisiliquum (NOGUEIRA et al., 2014), Tabebuia roseoalba (ABBADE; TAKAKI, 2014), Jatropha curcas (SILVA et al., 2017), Platymiscium floribundum, Lonchocarpus mueblbergianus e Acacia polyphylla (MASULLO et al., 2017), Libidibia ferrea (CARVALHO et al., 2017) e entre outros, ainda carece de procedimentos adequados para sementes de outras espécies, sobretudo, as recalcitrantes e de germinação lenta.

Determinar o protocolo de avaliação da viabilidade das sementes da $B$. excelsa pelo teste de tetrazólio tem sido um desafio na ciência desde o século passado quando Reis et al. (1979), pretenderam localizar o embrião e mais tarde Camargo et al. (1997), estabelecerem padrões de coloração para avaliar a viabilidade das sementes. Sendo assim, a proposta desse estudo foi de revisar e propor o protocolo para determinar a viabilidade das sementes da Bertholletia excelsa através do teste de tetrazólio.

\section{MATERIAL E MÉTODOS}

O estudo foi realizado com sementes da Bertholetia excelsa, safra 2016/2017 oriundas de plantio comercial propagado por enxertia com 16 anos de idade implantadas na Fazenda

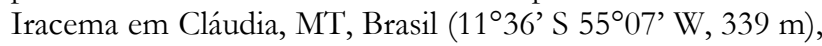
região da Amazônia Legal (Figura 1). Segundo a classificação de Köppen, o clima da região é o Aw (tropical quente úmido) com período chuvoso entre outubro a abril e o período seco de maio a setembro. As precipitações pluviais anuais são de aproximadamente $1970 \mathrm{~mm}$ e as temperaturas médias mensais variam entre 24 e $27^{\circ} \mathrm{C}$ (SOUZA et al., 2013).

A dispersão dos frutos pela planta mãe ocorre entre outubro a março nessa região, produzindo em média 17 sementes por fruto, as mesmas apresentam um tegumento rígido e lignificado, uma barreira física para a entrada de água no embrião (BORELLA et al., 2017). Os 35 frutos colhidos continham sementes com umidade média de 38,43\%, após armazenamento por 30 dias em local protegido a temperatura do ar média de $25,8^{\circ} \mathrm{C} \pm 2{ }^{\circ} \mathrm{C}$ e umidade relativa do ar média de $86 \% \pm 5 \%$, os frutos foram beneficiados com auxílio de serra copo acoplada em furadeira e as sementes foram destegumentadas com canivete.

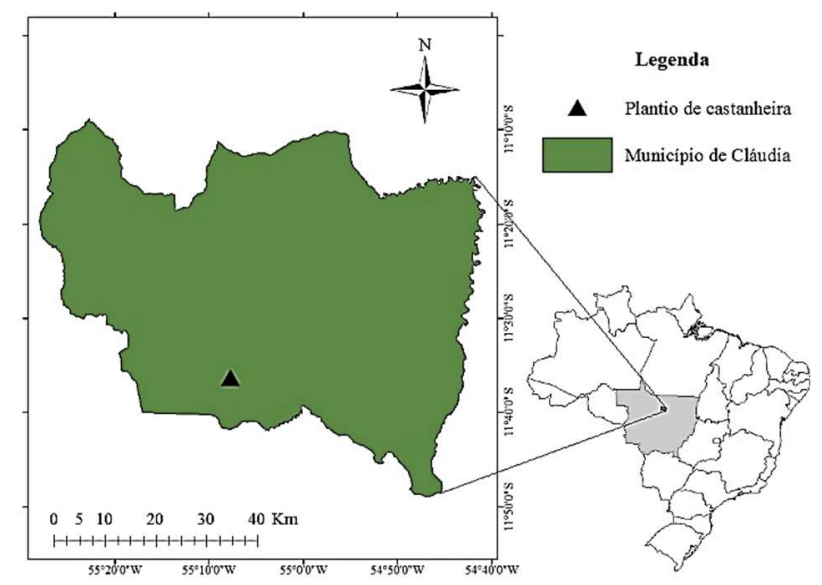

Figura 1. Localização do plantio comercial da B. excelsa no município de Cláudia, MT.

Figure 1. Location of the commercial planting in the municipality of Cláudia, MT.

Determinou-se a umidade de 50 sementes (equivalente a três ouriços) mantidas em estufa a $105{ }^{\circ} \mathrm{C} \pm 3{ }^{\circ} \mathrm{C}$ até a obtenção de massa constante, sendo cada semente uma repetição e, calculou-se a porcentagem de água inicial a partir da Equação 1 recomendado pelas Regras de Análises de Sementes (BRASIL, 2009).

$$
\mathrm{U}=\frac{(\mathrm{MI}-\mathrm{MF})}{\mathrm{MF}} .100
$$

em que: U - umidade (\%); MI e MF - massa inicial e final (g).

As 512 sementes destinadas ao teste de viabilidade foram pesadas antes e após a embebição, afim de obter a massa de água absorvida pelas sementes antes da aplicação da solução de tetrazólio.

A viabilidade das sementes foi testada pelo teste de tetrazólio, a partir da composição de 16 tratamentos (protocolos). Inicialmente, foi realizado um corte longitudinal entre os pólos de cada semente, conforme recomendado por Reis et al. (1979) e Camargo et al. (1997), para embebição em $200 \mathrm{ml}$ de água destilada sob forma de imersão direta (ID) e envolvidas em papel toalha Germitest ${ }^{\circledR}(\mathrm{PG})$ dentro de caixas de gerbox, acondicionadas em câmara de germinação BOD à temperatura de $30^{\circ} \mathrm{C}$ sem fotoperíodo, por 24 e $48 \mathrm{~h}$, sendo renovada a água a cada 24 h. Após a hidratação, as sementes de cada tratamento foram pesadas para determinar a umidade final e depois embebidas em solução incolor de 2, 3, 5 trifenil cloreto ou brometo de tetrazólio, nas concentrações de 0,1 e $0,5 \%$, por 12 e $24 \mathrm{~h}$, em ambiente escuro à temperatura de $30^{\circ} \mathrm{C}$ (Tabela 1$)$ e após a aplicação dos tratamentos as sementes foram lavadas em água corrente e mantidas em papel toalha umedecido até o final das avaliações. 
Tabela 1. Tratamentos de viabilidade de sementes da B. excelsa pelo teste de tetrazólio à $30^{\circ} \mathrm{C}$.

Table 1 . Viability treatments of $B$. excelsa seeds by tetrazolium test at $30^{\circ} \mathrm{C}$.

\begin{tabular}{ccccc}
\hline Tratamentos & FE & TE (horas) & TST (horas) & CST (\%) \\
\hline 1 & ID & 24 & 12 & 0,1 \\
2 & ID & 24 & 12 & 0,5 \\
3 & ID & 24 & 24 & 0,1 \\
4 & ID & 24 & 24 & 0,5 \\
5 & ID & 48 & 12 & 0,1 \\
6 & ID & 48 & 12 & 0,5 \\
7 & ID & 48 & 24 & 0,1 \\
8 & ID & 48 & 24 & 0,5 \\
9 & PG & 24 & 12 & 0,1 \\
10 & PG & 24 & 12 & 0,5 \\
11 & PG & 24 & 24 & 0,1 \\
12 & PG & 24 & 24 & 0,5 \\
13 & PG & 48 & 12 & 0,1 \\
14 & PG & 48 & 12 & 0,5 \\
15 & PG & 48 & 24 & 0,1 \\
16 & PG & 48 & 24 & 0,5 \\
\hline
\end{tabular}

FE: forma de embebição; ID: imersão direta; PG: papel toalha - Germitest ${ }^{\mathbb{R}}$ TE: tempo em embebição; TST: tempo em solução de tetrazólio; CST: concentração da solução de tetrazólio.

Os padrões colorimétricos das sementes foram obtidos através do sistema CIELAB da Comissão Internacional de Iluminação (International Commission on Illumination ou Comission Internationale de l'Eclairage) com o equipamento Chroma Meter CR-400/410 calibrado com iluminante C (Y: $87,0 ; \mathrm{x}: 0,3163 ; \mathrm{y}: 0,3234)$, que fornece as variáveis colorimétricas: L* - Luminosidade com escala de 0 (preto) a 100 (branco), $a^{*}$ - matizes do eixo vermelho $(+a)$ a verde $(-a)$ e b* - matizes do eixo amarelo (+b) a azul (-b), ambos com escala de +60 a -60 , além das variáveis $C$ - cromaticidade ou saturação com escala de 0 a 60 e h - ângulo de tinta ou tonalidade, ambos derivados dos valores de $\mathrm{a}^{*} \mathrm{e} \mathrm{b}^{*}$ (CAMARGOS; GONÇALEZ, 2001). As leituras colorimétricas foram realizadas ao final do teste de viabilidade, nas posições $\mathrm{A}$ e $\mathrm{C}$ - região dos pólos proximal e distal e B - região do embrião (Figura 2), sendo cinco repetições (sementes) por tratamento.

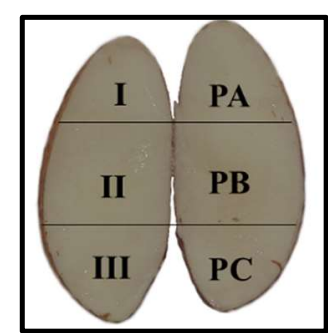

Figura 2. Representação das regiões de leitura das variáveis colorimétricas das sementes da B. excelsa, Cláudia, MT.

Figure 2. Representation of the reading regions of the colorimetric variables of $B$. excelsa seeds, Cláudia, MT.

Para avaliar os tratamentos de viabilidade aplicados nas sementes foram atribuídas escala numérica com base na tonalidade da coloração vermelho carmim observada nas sementes: $1<2<3<4$ e notas com base no grau de penetração: 1 (sem penetração, visível apenas na região de corte - 10 a 20 $\%$ da semente); 2 (penetração superficial - 20 a $40 \%$ da semente); 3 (penetração parcial - 40 a $60 \%$ da semente) a partir de um novo corte longitudinal nas outras $1 / 2$ sementes
(Figura 3). A atribuição de escalas para a tonalidade e notas para o grau de penetração da solução de tetrazólio nas sementes foi realizada a partir da descrição visual juntamente com a classificação das sementes viáveis.

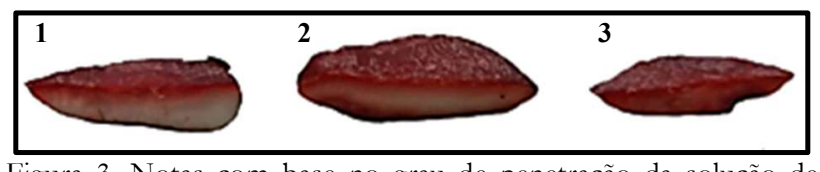

Figura 3. Notas com base no grau de penetração da solução de tetrazólio nas sementes da B. excelsa, Cláudia, MT.

Figure 3. Notes based on the degree of penetration of tetrazolium solution in B. excelsa seeds, Cláudia, MT.

O delineamento experimental foi inteiramente casualizado em esquema fatorial $2 \times 2 \times 2 \times 2$ (forma de embebição $\mathrm{x}$ tempo em embebição $\mathrm{x}$ tempo em solução de tetrazólio x concentração da solução de tetrazólio) com quatro repetições de 8 sementes cada. Os dados foram submetidos ao teste de normalidade por Shapiro-Wilk e homogeneidade pelo teste de Levene. Posteriormente à análise de variância e, quando significativas, as médias foram comparadas pelo teste de Scott-Knott a 5,0\% de probabilidade.

\section{RESULTADOS}

Houve distribuição normal dos valores de umidade inicial e após embebição das sementes da B. excelsa. A umidade inicial após armazenamento $24,47 \% \pm 5,88 \%$ e após a embebição por imersão direta e em papel toalha Germitest ${ }^{\circledR}$, ambas por 24 e 48 h, não apresentaram diferença $(p>0,05)$, independentemente da forma e do tempo em embebição, atingindo umidade média de $29,07 \% \pm 1,35 \%$ com incremento médio de $4,60 \%$ de umidade (Tabela 2 ).

Tabela 2. Umidade das sementes da B. excelsa submetidas a diferentes formas e tempos em embebição à $30^{\circ} \mathrm{C}$

Table 2. Humidity of $B$. excelsa seeds submitted to different forms and times in soaking at $30^{\circ} \mathrm{C}$.

\begin{tabular}{ccc}
\hline Embebição & Média \pm DP $(\%)$ & CV $(\%)$ \\
\hline ID 24h & $28,91 \pm 0,43^{*}$ & 1,48 \\
ID 48h & $29,11 \pm 2,18^{*}$ & 7,49 \\
PG 24h & $28,75 \pm 0,89 *$ & 3,11 \\
PG 48h & $29,51 \pm 1,27^{*}$ & 4,31 \\
\hline & $29,07 \pm 1,35^{*}$ & 4,66 \\
\hline
\end{tabular}

ID: imersão direta; PG: papel toalha Germitest ${ }^{\mathbb{B}}$; DP: desvio padrão; $\mathrm{CV}$ : coeficiente de variação; ${ }^{*}$ Não significativo pelo teste de Scott-Knott, p > 0,05 .

Independentemente dos tratamentos, não houveram diferenças das variáveis colorimétricas $(\mathrm{p}>0,05)$ entre as regiões dos pólos proximal e distal (A e C) e na região do embrião (B). Dessa forma, avaliou-se no agrupamento das leituras das variáveis colorimétricas medidas nas diferentes posições das sementes, possíveis diferenças entre os tratamentos aplicados, de modo que, foi evidenciado forte influência destes na obtenção da luminosidade, tonalidade e saturação da cor vermelho carmim nas sementes submetidas ao teste de tetrazólio (Figura 4).

Os valores de luminosidade $\left(\mathrm{L}^{*}\right)$ das sementes após o teste de tetrazólio variaram entre 26,11 (T8) a 41,19 (T9), indicando baixa luminosidade, com diferenças dos tratamentos T2, T4 e T14 em relação ao T8 (Tabela 3). Enquanto que, os valores de pigmentação $\mathrm{a}^{*} \mathrm{e} \mathrm{b}^{*}$ indicaram 
coloração vermelho e amarela, variando entre 21,92 a 39,16 e 7,45 a 19,42, nesta ordem. Observou-se que sementes dos tratamentos 1, 2, 5, 7 e 14 apresentaram cor vermelho mais clara que o T8 (Tabela 3).

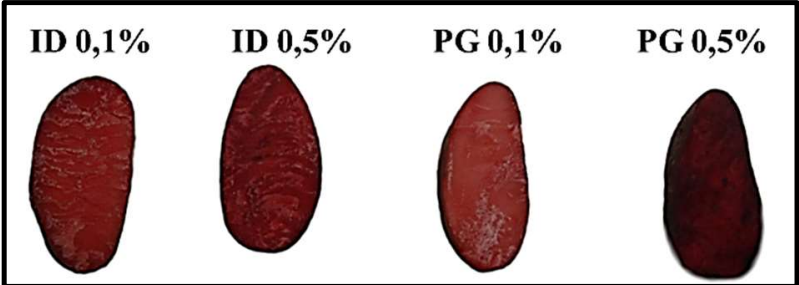

Figura 4. Padrão de coloração vermelho carmim nas sementes da $B$. excelsa submetidas ao teste de tetrazólio, Cláudia, MT.

Figure 4. Carmine red staining pattern of B. excelsa seeds submitted to the tetrazolium test, Cláudia, MT.

Os valores de tonalidade $\left(\mathrm{h}^{*}\right)$ foram baixos, com ângulo de tinta entre 16,58 (T8) e $26,35^{\circ}$ (T7), já os valores de saturação (C) da cor foram entre 23,14 (T8) e 43,07 (T14), representando a cor vermelho mais intensa e vivaz. Para ambas variáveis foi verificada que as sementes dos T2 e T14 apresentaram cor vermelho mais clara e vívida que as sementes do T8 que obteve tom mais escuro (Tabela 3).

Tabela 3. Valores médios das variáveis colorimétricas das sementes da $B$. excelsa submetidas a diferentes tratamentos pelo teste de tetrazólio.

Table 3. Mean values of colorimetric variables of B. excelsa seeds submitted to different treatments by tetrazolium test at $30^{\circ} \mathrm{C}$.

\begin{tabular}{cccccc}
\hline Trat. & $\mathrm{L}^{*}$ & $\mathrm{a}^{*}$ & $\mathrm{~b}^{*}$ & $\mathrm{~h}^{*}$ & $\mathrm{C}$ \\
\hline 1 & $34,67 \mathrm{c}$ & $37,89 \mathrm{a}$ & $16,85 \mathrm{~b}$ & $24,13 \mathrm{~b}$ & $40,56 \mathrm{a}$ \\
2 & $41,19 \mathrm{a}$ & $38,07 \mathrm{a}$ & $17,84 \mathrm{a}$ & $24,98 \mathrm{a}$ & $42,05 \mathrm{a}$ \\
3 & $29,30 \mathrm{e}$ & $30,47 \mathrm{c}$ & $11,74 \mathrm{~d}$ & $20,79 \mathrm{c}$ & $32,74 \mathrm{c}$ \\
4 & $38,47 \mathrm{~b}$ & $36,42 \mathrm{a}$ & $16,42 \mathrm{~b}$ & $24,12 \mathrm{~b}$ & $39,99 \mathrm{a}$ \\
5 & $34,51 \mathrm{c}$ & $38,09 \mathrm{a}$ & $16,54 \mathrm{~b}$ & $23,05 \mathrm{~b}$ & $41,63 \mathrm{a}$ \\
6 & $34,51 \mathrm{c}$ & $34,72 \mathrm{~b}$ & $13,94 \mathrm{c}$ & $21,50 \mathrm{c}$ & $37,45 \mathrm{~b}$ \\
7 & $31,27 \mathrm{~d}$ & $39,16 \mathrm{a}$ & $15,90 \mathrm{~b}$ & $21,65 \mathrm{c}$ & $42,35 \mathrm{a}$ \\
8 & $26,11 \mathrm{f}$ & $21,92 \mathrm{~d}$ & $7,45 \mathrm{f}$ & $16,58 \mathrm{~d}$ & $23,14 \mathrm{~d}$ \\
9 & $31,95 \mathrm{~d}$ & $33,98 \mathrm{~b}$ & $14,27 \mathrm{c}$ & $22,43 \mathrm{~b}$ & $37,30 \mathrm{~b}$ \\
10 & $30,60 \mathrm{~d}$ & $33,46 \mathrm{~b}$ & $13,55 \mathrm{c}$ & $21,60 \mathrm{c}$ & $36,31 \mathrm{~b}$ \\
11 & $27,95 \mathrm{f}$ & $29,71 \mathrm{c}$ & $10,59 \mathrm{e}$ & $19,52 \mathrm{c}$ & $31,58 \mathrm{c}$ \\
12 & $29,77 \mathrm{e}$ & $31,47 \mathrm{c}$ & $11,62 \mathrm{~d}$ & $20,11 \mathrm{c}$ & $33,58 \mathrm{c}$ \\
13 & $31,94 \mathrm{~d}$ & $36,64 \mathrm{a}$ & $16,11 \mathrm{~b}$ & $23,24 \mathrm{~b}$ & $40,14 \mathrm{a}$ \\
14 & $37,12 \mathrm{c}$ & $38,32 \mathrm{a}$ & $19,42 \mathrm{a}$ & $26,35 \mathrm{a}$ & $43,07 \mathrm{a}$ \\
15 & $29,44 \mathrm{e}$ & $34,24 \mathrm{~b}$ & $13,00 \mathrm{c}$ & $20,68 \mathrm{c}$ & $36,78 \mathrm{~b}$ \\
16 & $29,28 \mathrm{e}$ & $32,50 \mathrm{c}$ & $12,80 \mathrm{c}$ & $19,76 \mathrm{c}$ & $35,24 \mathrm{~b}$ \\
\hline Média & 32,38 & 34,19 & 14,25 & 21,91 & 37,12 \\
CV (\%) & 12,38 & 11,22 & 21,11 & 12,36 & 12,39 \\
\hline
\end{tabular}

$\mathrm{L}^{*}$ : luminosidade, $\mathrm{a}^{*}$ e $\mathrm{b}^{*}$ : coordenadas cromáticas, $\mathrm{C}^{*}$ : cromaticidade e $\mathrm{h}^{*}$ ângulo de tinta. CV: coeficiente de variação. Médias seguidas pela mesma letra na coluna, não diferem entre si pelo teste de Scott Knott, p > 0,05.

A forma de embebição e a concentração da solução de tetrazólio influenciaram na tonalidade da cor vermelho carmim nas sementes, sobretudo, o aumento da concentração do sal tetrazólio para $0,5 \%$ em imersão direta e em papel toalha Germitest ${ }^{\circledR}$ (Figura 5).

A penetração da solução de tetrazólio nas sementes não foi uniforme, independentemente do tratamento, grande parte das sementes $71,48 \%$ não apresentaram penetração, ou seja, visível apenas na região de ruptura dos tecidos das sementes, $21,69 \%$ penetração superficial e $6,84 \%$ penetração parcial (Tabela 4). Quando analisado os tratamentos individualmente para cada grau de penetração, foi observado diferença da forma de embebição em papel toalha Germitest ${ }^{\circledR}$ com aumento do percentual de sementes sem penetração e por imersão direta com aumento do percentual das sementes com penetração superficial da solução tetrazólio (Figura 6A).

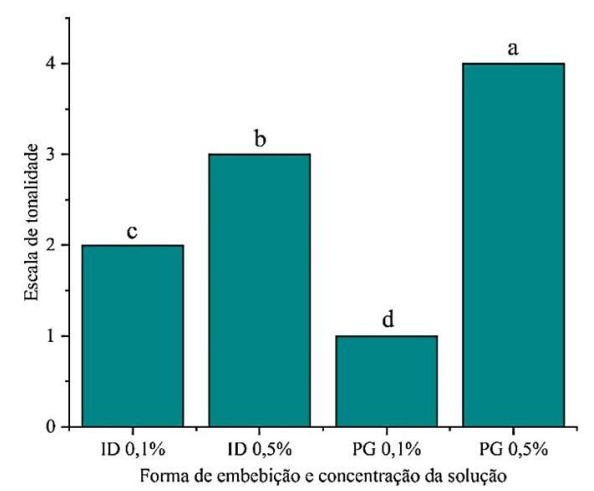

Figura 5. Escala de tonalidade das sementes da B. excelsa submetidas ao teste de tetrazólio, Sinop-MT. Médias comparadas entre si pelo teste de Scott-Knott a 5,0\% de probabilidade.

Figure 5. Tone scale of B. excelsa seeds submitted to the tetrazolium test, Sinop-MT. Means compared to each other by Scott-Knott test at $5.0 \%$ probability.

Os tempos em solução de 12 e $24 \mathrm{~h}$ na concentração de $0,1 \%$ da solução de tetrazólio influenciaram para o aumento do percentual de sementes sem penetração em torno de $84,00 \%$, o mesmo comportamento foi observado para os tempos em embebição de 24 e 48 h na concentração de $0,1 \%$ da solução com 75,78 e 92,19\% das sementes (Figura 6B e C). Enquanto que, o aumento do tempo em embebição para $48 \mathrm{~h}$ na concentração de $0,5 \%$ da solução permitiu aumento significativo de $32,81 \%$ de sementes com penetração superficial (Figura 6D). Reis et al. (1979), relataram que os tempos de 10 a 20 min em solução de tetrazólio a $0,5 \%$ sob temperatura de $45{ }^{\circ} \mathrm{C}$ permitiram melhor contraste de coloração no interior das sementes, sendo possível localizar na região central o embrião da semente.

Fogaça et al. (2011), padronizaram o protocolo do teste de tetrazólio das espécies florestais Copaifera langsdorffii e Schizolobium parabyba, recomendando utilizar sementes tegumentadas com escarificação mecânica embebidas em papel filtro, sendo para C. langsdorffii $24 \mathrm{~h}$ de embebição e tempo em solução de 4 h a $0,2 \%$ da concentração do sal, enquanto que para $S$. parabyba 48 h de embebição e tempo de solução de 4 h a $0,1 \%$ da concentração do sal, ambas à temperatura de $35{ }^{\circ} \mathrm{C}$ no escuro. Para avaliar a qualidade fisiológica de sementes de girassol pelo teste de tetrazólio Silva et al. (2013), constataram que a imersão direta em água por $16 \mathrm{~h}$ a $25^{\circ} \mathrm{C}$ combinada com o tempo de solução de tetrazólio de $3 \mathrm{~h}$ a $30{ }^{\circ} \mathrm{C}$ na concentração de $0,1 \%$ foi eficiente para colorir e classificar a viabilidade e vigor dessas sementes.

Os tratamentos 4 (ID 24h 24h 0,5\%), 8 (ID $48 \mathrm{~h} 24 \mathrm{~h}$ $0,5 \%$ ) e 10 (PG 24h $12 \mathrm{~h} 0,5 \%$ ) permitiram maior percentual de sementes 21,88\% com penetração parcial (Figura 6E e Figura 7). Contudo, em nenhum dos tratamentos foi evidenciada penetração total nas sementes pela solução de tetrazólio. 
Tabela 4. Grau de penetração da solução de tetrazólio nas sementes da B. excelsa submetidas a diferentes tratamentos à $30^{\circ} \mathrm{C}$. Table 4. Degree of penetration of tetrazolium solution in B. excelsa seeds submitted to different treatments at $30{ }^{\circ} \mathrm{C}$.

\begin{tabular}{cccc}
\hline \multirow{2}{*}{ Tratamentos } & \multicolumn{3}{c}{ Grau de penetração } \\
\cline { 2 - 3 } & 1 & 2 & 3 \\
\hline 1 & $68,75 \mathrm{~b}$ & $21,88 \mathrm{a}$ & $9,38 \mathrm{~b}$ \\
3 & $65,50 \mathrm{~b}$ & $25,00 \mathrm{a}$ & $12,50 \mathrm{~b}$ \\
4 & $71,88 \mathrm{~b}$ & $28,13 \mathrm{a}$ & $2,00 \mathrm{c}$ \\
5 & $40,63 \mathrm{c}$ & $37,58 \mathrm{a}$ & $0,00 \mathrm{c}$ \\
6 & $90,63 \mathrm{a}$ & $9,38 \mathrm{~b}$ & $3,13 \mathrm{c}$ \\
7 & $56,25 \mathrm{~b}$ & $40,63 \mathrm{a}$ & $0,00 \mathrm{c}$ \\
8 & $84,38 \mathrm{a}$ & $15,63 \mathrm{~b}$ & $21,88 \mathrm{a}$ \\
9 & $46,88 \mathrm{c}$ & $3,13 \mathrm{c}$ \\
10 & $78,13 \mathrm{a}$ & $21,88 \mathrm{a}$ \\
11 & $65,50 \mathrm{~b}$ & $31,25 \mathrm{a}$ & $0,00 \mathrm{c}$ \\
13 & $84,38 \mathrm{a}$ & $18,75 \mathrm{~b}$ & $12,5 \mathrm{~b}$ \\
14 & $65,63 \mathrm{~b}$ & $15,63 \mathrm{~b}$ & $0,00 \mathrm{c}$ \\
Coeficiente de variação (\%) & $96,88 \mathrm{a}$ & $15,63 \mathrm{~b}$ & $0,00 \mathrm{c}$ \\
\hline Média (\%) & $21,88 \mathrm{a}$ & $0,00 \mathrm{c}$ \\
\hline
\end{tabular}

Médias seguidas pela mesma letra na coluna, não diferem entre si pelo teste de Scott Knott, $\mathrm{p}>0,05$.

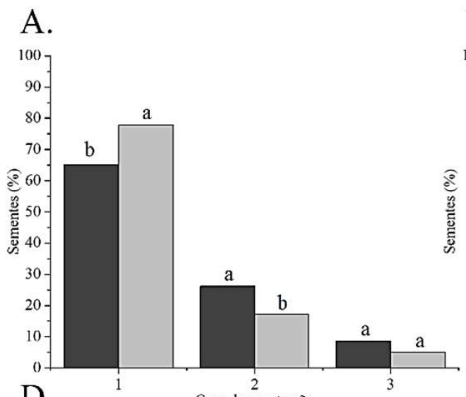

D.

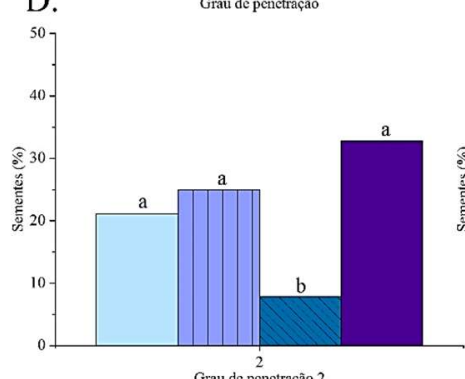

B.

E.

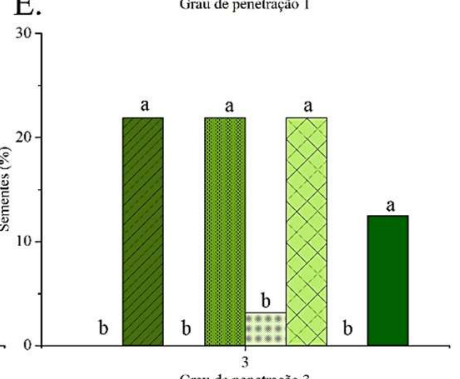

Grau de penetracăo 3

C.

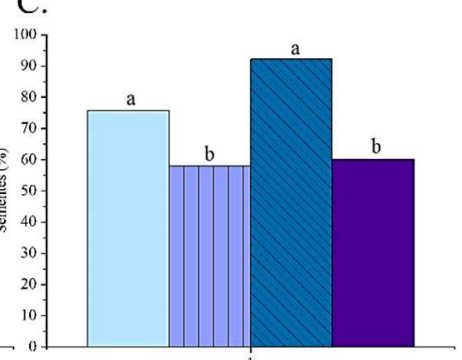

Grau de penetraçåo 1

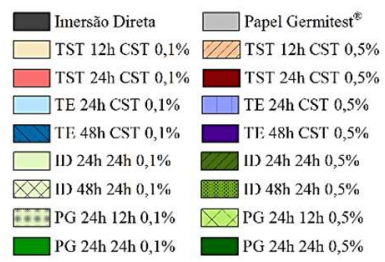

PG 24h 24h $0,1 \%$ PG $24 \mathrm{~h} 2 \mathrm{~h}, 0,5 \%$

Figura 6. A - grau de penetração da solução de tetrazólio nas sementes da B. excelsa quanto a forma de embebição; B, C e D - grau de penetração 1 e 2 nos tempos em embebição (TE) e em solução (TST) e na concentração (CST) da solução de tetrazólio; E - grau de penetração 3 quanto a forma e tempo em embebição, tempo e concentração da solução de tetrazólio. Médias comparadas entre si pelo teste de Scott-Knott a 5,0\% de probabilidade.

Figure 6. A- degree of penetration of tetrazolium solution in B. excelsa seeds as to the imbibition form; B, C and D - degree of penetration 1 and 2 in the soaking (TE) and solution (TST) times and the tetrazolium solution concentration (CST); E - degree of penetration 3 as to the form and time in imbibition, time and concentration of the tetrazolium solution. Means compared to each other by Scott-Knott test at $5.0 \%$ probability.

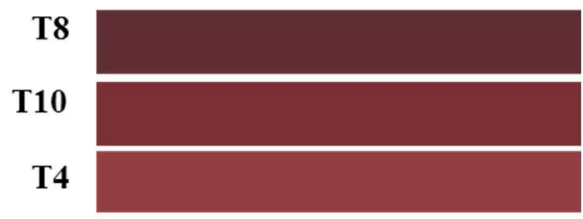

Figura 7. Representação da coloração das sementes da B. excelsa submetidas ao teste de tetrazólio, Sinop-MT. Fonte: https://www.nixsensor.com/free-color-converter/

Figure 7. Representation of staining of B. excelsa seeds submitted to the tetrazolium test, Sinop-MT. Source: https://www.nixsensor.com/free-color-converter/ 


\section{DISCUSSÃO}

Vale ressaltar que não foi realizado o teste de germinação das sementes da B. excelsa, e que o propósito deste estudo foi de revisar o protocolo de viabilidade de sementes pelo teste de tetrazólio para essa espécie. Dessa forma, diante dos resultados apresentados, os diferentes tratamentos propostos atenderam os critérios (BRASIL, 2009) para o teste de tetrazólio, por permitirem a coloração vermelho carmim e penetração da solução de tetrazólio nas sementes, como indicativo da viabilidade das sementes da B. excelsa mesmo com baixo grau de umidade.

A determinação da viabilidade de sementes florestais pelo teste de tetrazólio é confiável, de fácil interpretação e permite obter resultados rápidos (MASULLO et al., 2017), caso contrário, atestar a viabilidade de sementes por meio do processo germinativo pode levar tempo, uma vez que, existem espécies de germinação lenta e desuniforme como é o caso da B. excelsa (MÜLLER et al., 1980), o que possivelmente tornaria inviável economicamente testar sua viabilidade através da germinação.

A hidratação das sementes antes da aplicação do teste de tetrazólio é fundamental para penetração da solução de tetrazólio, além da uniformidade da umidade das sementes após embebição para interpretação correta do teste de tetrazólio durante a classificação da viabilidade das sementes. O teste de tetrazólio distingui tecidos vivos das sementes, a partir da redução do sal 2, 3, 5 trifenil cloreto ou brometo de tetrazólio que reage com os íons de hidrogênio liberados da respiração celular, resultando a substância vermelha, estável, não difusível chamado trifenilformazan colorindo assim, os tecidos vivos diferindo-os de tecidos mortos das sementes que mantêm a cor original (ABBADE; TAKAKI, 2014).

Ambas as formas de embebição em imersão direta e umedecimento lento no papel Germitest ${ }^{\circledR}$ não influenciam na integridade das sementes e permitiram um aumento uniforme do conteúdo de água das mesmas, sendo aplicável ambos os métodos para testes de viabilidade das sementes da B. excelsa. Contudo, a embebição em imersão direta em água pode causar danos em sementes de determinadas espécies (BRASIL, 2009).

Os tratamentos considerados mais adequados foram 4 (ID 24 h 24 h 0,5\%), 8 (ID 48 h 24 h 0,5\%), e 10 (PG 24 h 12 h 0,5\%), devido ao maior percentual de sementes com penetração parcial (nota 3), que confere maior confiabilidade para a classificação de sementes viáveis e inviáveis. Além do fato da coloração (vermelho fraco normal) e tonalidade das sementes pela solução de tetrazólio ter indicado sementes com potencial fisiológico com a consistência dos tecidos túrgidos e em atividade fisiológica, devido a coloração (FRANÇA-NETO et al., 2019).

Foi observado em apenas 2, 3 e 5 sementes dos T1, T2 e T9, respectivamente, a região do embrião com a cor vermelho carmim escura e após o corte da $1 / 2$ semente foi verificado embrião com aspecto branco leitoso, o que caracteriza sementes inviáveis (BRASIL, 2009) pelo teste de tetrazólio (Figura 8). Camargo et al. (1997), afirmam que a deterioração das sementes da B. excelsa inicia-se pelo embrião e expande-se para as regiões periféricas, fato evidenciado neste estudo. Os mesmos autores relataram que a deterioração e perda de viabilidade dessas sementes estão relacionados à redução do grau de umidade durante o período de armazenamento.

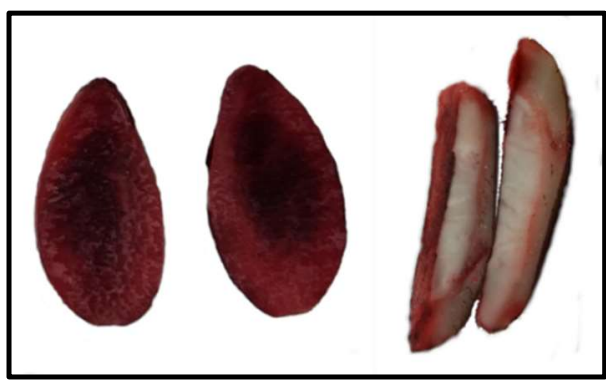

Figura 8. Sementes da B. excelsa consideradas inviáveis pelo teste de tetrazólio, Cláudia, MT.

Figure 8. B. excelsa seeds considered inviable by tetrazolium test, Cláudia, MT.

Jose et al. (2018) relatam que o tempo, ambiente e o tipo de embalagem para armazenamento, influenciam nas taxas de perda de água das sementes de Jatropha curcas oleaginosa e ortodoxa. Segundo Barbedo (2018) sementes ortodoxas podem sobreviver com um teor mínimo de água por um determinado tempo, enquanto que, sementes recalcitrantes são sensíveis à dessecação e com baixa possibilidade de armazenamento por longo período de tempo.

Em sementes sob condições de dessecação, pode ocorrer o aumento na produção de espécies reativas de oxigênio ou diminuir a eficiência das atividades antioxidativas induzindo a processos oxidativos degradantes, mudança em atividades da peroxidação lipídica e danos no sistema de membranas influenciando na qualidade fisiológica, bem como, na viabilidade das sementes (PAMMENTER; BERJAK, 2014). Os autores ainda afirmam que, sementes recalcitrantes apresentam grande variabilidade na quantidade de perda de água que pode ser tolerada, bem como à taxa de secagem. Figueirêdo et al. (1990) avaliaram a germinação de sementes da B. excelsa com umidades diferentes e afirmaram que as mesmas não devem ser secadas a níveis inferior a 14\%, quando o objetivo é a produção de mudas.

A qualidade fisiológica de semente também está associada a maturidade fisiológica (SILVA et al., 2017). Müller et al. (1980) explicam que pode ocorrer a dispersão de frutos prematuros da $B$. excelsa, fato que pode estar relacionado ao balanço hormonal, em complemento Camargo et al. (2000) afirmam que as sementes da $B$. excelsa não apresentam tecidos em diferenciação avançada no momento da maturação e dispersão da semente, como os que formam a plúmula, radícula e cotilédones que são comuns em sementes. Barbedo (2018) relata a incrível estratégia de algumas espécies em alongar e antecipar seu ciclo de maturação, dependendo das condições ambientais a dispersão das sementes pode ocorrer em períodos anteriores à maturação, produzindo sementes com diferentes graus de recalcitrância. Algumas das possíveis razões de difícil avaliação da qualidade fisiológica e germinação dessas sementes.

A concentração da solução de tetrazólio a $0,5 \%$ foi eficiente em destacar os tecidos, independentemente da forma de embebição. Estudos de viabilidade de sementes da B. excelsa pelo teste de tetrazólio também identificaram a concentração de $0,5 \%$ como adequada para coloração dos tecidos vivos e classificação da viabilidade dessas sementes (REIS et al., 1979; CAMARGO et al., 1997), bem como para Ceiba speciosa (LAZAROTTO et al., 2011), Platymiscium floribundum e Acacia polyphylla (MASULLO et al., 2017). 
A temperatura de hidratação e de embebição em solução de tetrazólio pode ter influenciado na penetração da solução nas sementes. Sabe-se que o fluxo de água para dentro da semente na fase I do padrão trifásico da germinação ocorre por diferença de potencial matricial com o ambiente, esse processo é puramente físico, quando em conjunto com o aumento da temperatura do ar, contribui para aumentar a viscosidade da água e, consequentemente, aumenta a velocidade de absorção da água pela semente (CARVALHO et al., 2017).

A composição lipídica da semente dificulta a entrada de água. Assim, os tempos de embebição e de solução podem ter sido influenciados pela composição lipídica das sementes para penetração completa da solução. Aumentar o tempo de embebição seria uma alternativa para verificar se a falta da penetração da solução de tetrazólio é devido à lenta absorção ou se é um indicativo de dano na semente.

Assim, recomenda-se para novos estudos aumentar a temperatura e/ou o tempo de embebição, além de testar a viabilidade das sementes de B. excelsa de diferentes origens, como a nativa e a enxertada. Avaliar também o tempo e local de armazenamento, além do grau de umidade no momento da colheita das sementes, já que são sementes recalcitrantes com rápida perda de umidade tornando-se vulneráveis à deterioração durante a armazenagem.

De modo geral, revisar e estabelecer um protocolo para viabilizar o teste de tetrazólio sem a necessidade de acompanhamento do teste de germinação para determinar a qualidade fisiológica das sementes da $B$. excelsa é essencial para a obtenção de resultados rápidos e acurado, na perspectiva de oportunizar a propagação da espécie tanto para fins comerciais na inserção em sistemas produtivos e extração de frutos e sementes, quanto ambientais na recomposição em áreas de vegetação nativa e manutenção do ecossistema.

\section{CONCLUSÕES}

O teste de tetrazólio é eficiente para avaliar a viabilidade das sementes da Bertholletia excelsa substituindo o teste de germinação.

A viabilidade das sementes da Bertholletia excelsa pode ser aferida com sementes destegumentadas e partidas ao meio em: embebição em imersão direta em água por $24 \mathrm{~h}$ e concentração de $0,5 \%$ do sal tetrazólio por 24 h à $30{ }^{\circ} \mathrm{C}$ e também por embebição em papel toalha Germitest ${ }^{\circledR}$ por 24 $\mathrm{h}$ e concentração de $0,5 \%$ do sal tetrazólio por $12 \mathrm{~h}$ à $30^{\circ} \mathrm{C}$.

\section{REFERÊNCIAS}

ABBADE, L. C.; TAKAKI, M. Teste de tetrazólio para avaliação da qualidade de sementes de Tabebuia roseoalba (Ridl.) Sandwith - Bignoniaceae, submetidas ao armazenamento. Revista Árvore, Viçosa, v. 38, n. 2, p. 233-240, 2014. DOI: https://dx.doi.org/10.1590/S010067622014000200003

BARBEDO, C. J. A new approach towards the so-called recalcitrant seeds. Journal of Seed Science, Brasília, v. 40, n. 3, p. 221-236, 2018. DOI: http://dx.doi.org/10.1590/2317-1545v40n3207201

BORELLA, D. R.; SILVA, A. C.; SOUZA, A. P.; BOUVIÉ, L.; NOGUEIRA, L. A. S.; PEREIRA, C. A. L.; SILVA, M. A. L. V. Biometria de frutos e sementes da castanheira-do-Brasil da região Médio-Norte do Mato
Grosso. Nativa, Sinop, v. 5, esp., p. 483-490, 2017. DOI: http://dx.doi.org/10.5935/2318-7670.v05nespa01

BOUVIE, L.; BORELLA, D. R.; PORTO, P. A. O.; SILVA, A. C.; LEONEL, S. Caracterização físico-química dos frutos de castanheira do Brasil. Nativa, Sinop, v. 4, n. 2, p. 107-111, 2016. DOI: http://dx.doi.org/10.14583/2318-7670.v04n02a10

BRASIL_MINISTÉRIO DA AGRICULTURA E REFORMA AGRÁRIA. Regras para análise de sementes. Brasília: Mapa/ACS, 2009. 399 p.

CAMARGO, I. P. de; CARVALHO, M. M. de; VIEIRA, M. das G. G. C. Avaliação da deterioração em sementes de castanheira-do-Brasil pelo teste de tetrazólio. Pesquisa Agropecuária Brasileira, Brasília, v. 32, n. 8, p. 835-839, 1997.

CAMARGO, I. P.; CASTRO, E. M.; GAVILANES, M. L. Aspectos da anatomia e morfologia de amêndoas e plântulas de Castanheira-do-Brasil. Cerne, Lavras, v. 6, n. 2, p. 11-18, 2000.

CAMARGOS, J. A. A.; GONÇALEZ, J. C. A colorimetria aplicada como instrumento na elaboração de uma tabela de cores de madeira. Brasil Florestal, Brasília, v. 20, n. 71, p. 30-41, 2001.

CARVALHO, S. M. C.; TORRES, S. B.; BENEDITO, C. P.; NOGUEIRA, N. W.; SOUZA, A. A. T.; NETA, M. L. de S. Viability of Libidibia ferrea (Mart. ex Tul.) L. P. Queiroz var. ferrea) seeds by tetrazolium test. Journal of Seed Science, Londrina, v. 39, n. 1, p. 7-12, 2017. DOI: http://dx.doi.org/10.1590/2317-1545v39n1163784

COSTA, M. G.; TONINI, H.; FILHO, P. M. Atributos do Solo Relacionados com a Produção da Castanheira-doBrasil (Bertholletia excelsa). Floresta e Ambiente, Seropédica, v. 24, e20150042, 2017. DOI: https://dx.doi.org/10.1590/2179-8087.004215

FIGUEIRÊDO, F. J. C.; CARVALHO, J. E. U. de; FRAZÂO, D. A. C. Nível crítico de umidade e seus efeitos sobre a emergência de plântulas de castanhado-Brasil. Belém: Embrapa - CPATU, 1990. 17 p.

FOGAÇA, C. A.; KROHN, N. G.; SOUZA, M. de A.; PAULA, R. C. de. Teste de tetrazólio em sementes de Copaifera langsdorffi e Schizolobium parabyba. Floresta, Curitiba, v. 41, n. 4, p. 895-904, 2011. DOI: http://dx.doi.org/10.5380/rf.v41i4.25352

FRANÇA-NETO, J. B.; KRZYZANOWSKI, F. C.; COSTA, N. P. da. O teste de tetrazólio em sementes de soja. Londrina: EMBRAPA-CNPSo, 1998. 72 p.

FRANÇA-NETO, J. de B.; KRZYZANOWSKI, F. C. Tetrazolium: an important test for physiological seed quality evaluation. Journal of Seed Science, Londrina, v. 41 , n. 3, p. 359-366, 2019. DOI: http://dx.doi.org/10.1590/2317-1545v41n3223104

IBGE_INSTITUTO BRASILEIRO DE GEOGRAFIA E ESTATÍSTICA. Produção da extração vegetal e da silvicultura 2018. Rio de Janeiro: IBGE, 2018. 33 v. 8 p.

JOSE, S. C. B. R.; SALOMÃO, A. N.; MELO, L. A. M. P. de; SANTOS, I. R. I.; LAVIOLA, B. G. Germination and vigor of stored Jatropha (Jatropha curcars L.) seeds. Journal of Seed Science, Londrina, v. 40, n. 1, p. 52-59, 2018. DOI: 1545v40n1183431

LAZAROTTO, M. L.; PIVETA, G.; MUNIZ, M. F. B.; REINIGER, L. R. S. Adequação do teste de tetrazólio para avaliação da qualidade de sementes de Ceiba speciosa. Semina: Ciências Agrárias, Londrina, v. 32, n. 4, p. 
1243-1250,

2011.

DOI: http://dx.doi.org/10.5433/1679-0359.2011v32n4p1243

MASULLO, L. S.; PIÑA-RODRIGUES, F. C. M.; FIGLIOLIA, M. B.; AMÉRICO, C. Optimization of tetrazolium tests to assess the quality of Platymiscium floribundum, Lonchocarpus mueblbergianus and Acacia polyphylla DC. seeds. Journal of Seed Science, Londrina, v. 39, n. 2, p. 189-197, $2017 . \quad$ DOI: http:/ /dx.doi.org/10.1590/2317-1545v39n2167534

MÜlleR, C. H.; RODRIGUES, I. A.; MÜlLER, A. A.; MÜLLER, N. R. M. Castanha-do-Brasil: resultados de pesquisa. Belém: EMBRAPA - CPATU, 1980. 25 p.

NOGUEIRA, N. W.; TORRES, S. B.; FREITAS, R. M. O. de. Teste de tetrazólio em sementes de timbaúba. Semina: Ciências Agrárias, Londrina, v. 35, n. 6, p. 2967-2976, 2014.

DOI: http://dx.doi.org/10.5433/1679-0359.2014v35n6p2967

PAMMENTER, N. W.; BERJAK, P. Physiology of desiccation-sensitive (recalcitrant) seeds and the implications for cryopreservation. International Journal of Plant Sciences, Chicago, v. 175, n. 1, p. 21-28, 2014. DOI: https://dx.doi.org/10.1086/673302

PARAÍSO, H. A.; JUNIOR, D. da S. B.; AVELAR, R. I. S.; COSTA, C. A. da; GOMES, L. S. de P.; NASCIMENTO, W. M. Adjustments in the tetrazolium test methodology for assessing the physiological quality of chickpea seeds. Journal of Seed Science, Londrina, v. 41, n. 1, p. 7-12, 2019. DOI: http://dx.doi.org/10.1590/23171545v41n1187777

REIS, G. G. dos; CARVALHO, J. E. U. de; MULLER, C. H.; FIGUEIREDO, F. J. C. Calibração do teste de tetrazólio em sementes de castanha-do-Brasil. Belém: EMBRAPA - CPATU, 1979. 9 p. (Comunicado Técnico, 17).

REZENDE, R. G.; JESUS, L. L. de; NERY, M. C.; ROCHA, A. de S.; CRUZ, S. M.; ANDRADE, P. C. de R. Teste de tetrazólio em sementes de crambe. Semina: Ciências Agrárias, Londrina, v. 36, n. 4, p. 2539-2544, 2015. DOI: http:/ /dx.doi.org/10.5433/1679-0359.2015v36n4p2539
RODRIGUES, V. O.; PENIDO, A. C.; OLIVEIRA, A. M. S.; AVILA, M. A. B.; SOUSA, D. V. L. de; OLIVEIRA, J. A. Adequacy of the tetrazolium test methodology for Stylosanthes capitata Vogel seeds. Journal of Seed Science, Londrina, v. 40, n. 4, p. 435-441, 2018. DOI: http://dx.doi.org/10.1590/2317-1545v40n4192968

SILVA, R. C. da; GRZYBOWSKI, C. R. de S.; FRANÇA-NETO, J. de B.; PANOBIANCO, M. Adaptação do teste de tetrazólio para avaliação da viabilidade e do vigor de sementes de girassol. Pesquisa Agropecuária Brasileira, Brasília, v. 48, n. 1, p. 105-113, 2013. DOI: http://dx.doi.org/10.1590/S0100204X2013000100014

SILVA, L. J. da; DIAS, D. C. F. dos S.; OLIVEIRA, G. L.; JÚNIOR, R. A. da S. The effect of fruit maturity on the physiological quality and conservation of Jatropha curcas seeds. Revista Ciência Agronômica, Fortaleza, v. 48, n. 3, p. 487-495, 2017.

SOUZA, A. P.; MOTA, L. L.; ZAMADEI, T.; MARTIM, C. C.; ALMEIDA, F. T.; PAULINO, J. Classificação climática e balanço hídrico climatológico no estado de Mato Grosso. Nativa, Sinop, v. 1, n. 1, p. 34-43, 2013. DOI: http://dx.doi.org/10.14583/23187670.v01n01a07

TEIXEIRA, R. A.; PEDROZO, C. Â.; COSTA, E. K. L. da; BATISTA, K. D.; TONINI, H.; PESSONI, L. A. Correlações e divergência fenotípica entre genótipos cultivados de castanha-do-Brasil. Scientia Forestalis, Piracicaba, v. 43, n. 107, p. 523-531, 2015.

TONINI, H.; BALDONI, A. B.; HOOGERHEIDE, E. S. S.; BOTELHO, S. de C. C. Caracterização e rentabilidade do sistema extrativista da castanha-do-brasil praticado em Itaúba (MT). Nativa, Sinop, v. 5, n. 3, p. 175-181, 2017. DOI: http://dx.doi.org/10.5935/2318-7670.v05n03a04

YANG, J. Brazil nuts and associated health benefits: A review. LWT - Food Science and Technology, Sheffield, v. 42, n. 10, p. 1573-1580, 2009. DOI: https://dx.doi.org/10.1016/j.lwt.2009.05.019 